\title{
Una imagen fantasmagórica: modernidad, capitalismo y religión en Walter Benjamin*
}

\author{
A Phantasmagorical Image: Modernity, Capitalism and Religion \\ in Walter Benjamin
}

\section{Pedro Pérez Díaz ${ }^{* *}$}

\section{Resumen}

El análisis del texto póstumo de Benjamin, titulado Capitalismo como religión evidencia un diagnóstico certero del devenir del capitalismo del siglo XX y XXI, en donde su aspecto cultual se ha adosado a las imágenes que habitan la ciudad y en cierto sentido, la constituyen, reconfigurando a su vez, su trazado urbano. La noción de fantasmagoría será clave para comprender cómo esta religión capitalista se ha introducido y totalizado en la vida de los hombres en cuanto ha hecho del espacio una imagen para-sí del capital, estando por lo tanto, intrínsecamente ligada a una política fantasmagórica que requiere la ciudad para la perpetuación de su culto.

Palabras clave: culto; Dios; crédito; ciudad; flâneur.

\begin{abstract}
The analysis of the posthumous text of Benjamin, titled Capitalism as religion, show a certeral diagnosis about the progression of capitalism of XX and XXI century, in which its cult aspect have been attached to the images that dwell the city, and in some way, it constitute her, recon-

\footnotetext{
* Recibido: 6/12/2018. Aceptado: 12/12/2018.

${ }^{* * *}$ Universidad Andrés Bello, Chile. Email: pedroj.pd@hotmail.com
} 
figurating at the same time, his urban planning. The notion of phantasmagoria it is key to understand how this capitalistic religion has been introduced and totalized in men life, in the sense that has transformed space in an image for-itself of capital, being, in conclussion, in an intrinsec union with a phantasmagorical politics that require the city for the perpetuation of his cult.

Keywords: cult; God; loan; city; flaneur.

Dios creó ante todo los cafés, las tiendas y los cines. Luego cafés, tiendas y cines, crearon hombres. Los crearon cuando ya el impulso primero de Dios empezó a amortiguarse y tuvieron que buscar sustento con sus propios medios. Dios, al ver esto, se sintió feliz. Luego vino una idea digna de Satanás:

“Si quitáramos al alimentado y dejáramos solo al alimento?”

Y bajo los pliegues de su capa celeste, escondió cafés, tiendas y cines, se los llevó al cielo y los guardó. Entonces los hombres, ya sin objetivo, sin razón de ser, echaron pelos se treparon a los árboles y aullaron

Juan Emar, Ayer

Se atribuye que alrededor del año 1921, Walter Benjamin redactó un texto titulado Capitalismo como religión (Kapitalismus als Religion), el cual fue publicado póstumamente, apareciendo recién en 1985. El mencionado texto se encuentra dentro de la tradición de escritura que legó Benjamin, esto, por su carácter fragmentario - no supera las tres páginas - y enigmático. Desde su lectura, el fenómeno del capitalismo se muestra, en primera instancia, como un parásito que surge a partir del origen del cristianismo, lo cual da pie para verlo como un sinónimo de religión, en el sentido de satisfacer los mismos malestares que daban respuestas las religiones establecidas. Al ver con detención este planteamiento, se desprende una crítica hacia el postulado de Max Weber de su obra La ética protestante y el espiritu de capitalismo (1905), donde el sociólogo alemán señala que el espíritu del capitalismo surge de la conducción de la vida de la fe protestante y su carácter racionalizante, más, se 
escinde de él cuando este nuevo espíritu se torna motor propio de su maquinaria y conducción ética, desligándose el capitalismo, por lo tanto, de su origen religioso, y perdiendo, por ende, esa esencialidad que Benjamin le atribuye; allí es cuando comparece por vez primera, la conocida analogía con la jaula de hierro. Para Weber,

De acuerdo con Baxter, la preocupación por los bienes exteriores debería estar sobre los hombros de sus santos sólo como «un abrigo fino que en todo momento uno se puede quitar». Pero la fatalidad hizo que el abrigo se convirtiera en una jaula de acero. Cuando el ascetismo se puso a reconstruir el mundo y a actuar en él, los bienes exteriores de este mundo ganaron sobre el ser humano un poder creciente y al final invencible, quién sabe si para siempre. En todo caso, el capitalismo victorioso ya no necesita este apoyo una vez que descansa en una base mecánica. (Weber, 2013, 259)

Pero así como Weber vislumbró esta conexión, antes que él, el mismo Marx hizo alusiones respecto de esta idea, principalmente en el apartado de El fetichismo de la mercancía (y su secreto) (2016) en el primer tomo de El Capital, pero también en otros lugares de su obra; como indica Alberto Toscano, esta vinculación entre los argumentos de Weber y Marx ya había sido planteada por Michael Löwy, pero desde los Grundrisse (Toscano, 2010, 17). En este análisis, Toscano remite a la Introducción a la crítica de la filosofia del derecho de Hegel, en donde ve que "en la medida en que la religión es a la vez una hipostasis y una manera de hacer frente, no sólo a las fuerzas naturales sino las sociales, se podría decir [...] que el cristianismo es en un sentido una teoría (o lógica) del capitalismo" (Toscano, 2010, 16).

Será entonces, la base mecánica que adquiere el capitalismo en su proceso de perfección, lo que permitirá el quiebre de esta relación originaria para Weber. A primera vista, ambas tesis tienen un contenido similar, sin embargo, como se ha mencionado, Benjamin la excede y radicaliza, pues el capitalismo nunca se ha escindido de su carácter religioso, y de hecho, será concebido por él como la nueva religión de la modernidad. Desde esta base, se analizarán las características propias de esta religión capitalista, su vinculación con el espacio y la literatura, para finalizar con un esbozo de una conexión indisociable entre imagen fantasmagórica y política fantasmagórica, la que inunda la ciudad en cuanto la habita, poniéndola al límite de su configuración estética. 


\section{La religión capitalista}

Allende el hecho de que este texto de Benjamin fue conocido tardíamente, no se puede leer sino como un diagnóstico certero respecto del actual devenir del capitalismo, no sólo comprendido éste como una teoría económica de los modos de producción, sino también como régimen estético de visualidad y fantasmagoría. Si bien, se trata de un texto fragmentario y un tanto críptico, el filósofo berlinés es claro al identificar ciertas características propias del capitalismo como religión. En sus palabras,

[...] el capitalismo es una religión cultual pura, tal vez la más extrema que haya habido. Nada tiene en él en ningún caso significado inmediato, si no es en relación al culto; no conoce dogmática específica, ni tampoco ninguna teleología [...] El capitalismo es ciertamente celebración de un culto producido sans trêve et sans merci $i^{1}$. No hay en él ningún «día ordinario», ni uno solo que no sea festivo en el brutal sentido del despliegue de la sagrada pompa en que consiste, de la tensión extrema del devoto. (Benjamin, 2017, 128)

De esta forma vemos que

El capitalismo es quizás el primer caso de un culto no absolutorio, sino, al contrario, culpabilizador [...] una enorme consciencia de culpa que no se sabe absolver recurre al culto, no para expiar en él la culpa, sino para hacerla universal, para meterla en la consciencia a martillazos y, por fin y ante todo, englobar a Dios mismo en esa culpa, para así finalmente interesarlo a él incluso en la expiación [...] La trascendencia de Dios se ha derrumbado. Pero él no ha muerto; está integrado en el destino humano. (Benjamin, 2017, 128-129)

Estas tres características refieren al capitalismo como una religión cultual, cuya permanencia es indefinida en cuanto totalizada en la vida de los hombres, y además, se trata de un culto esencialmente culpabilizador. Siguiendo la tercera característica del capitalismo como una religión, encontramos una interesante y no menor consideración en sus aspectos reformativos. Benjamin se refiere históricamente al capital no como un renovador del ser, sino al causante de su destrucción (Benjamin, 2017, 129). De allí que David Harvey

\footnotetext{
${ }^{1}$ Del francés "Sin tregua ni piedad"
} 
pueda afirmar que "la modernidad trata por ello de una 'destrucción creativa", ya sea moderada o democrática, traumática y autoritaria" (Harvey, 2008, 3); se podría afirmar conjuntamente, que esta destrucción creativa es precisamente la inauguración de esta nueva forma de ejercer el capitalismo, es decir, el capitalismo como religión. De esto surge la siguiente interrogante: ¿cómo leer de una forma actual dicha sentencia? Siguiendo la lectura del filósofo italiano Giorgio Agamben, encontramos un énfasis en el tema del crédito, ya que

[...] es aquello en lo que creemos, en lo que ponemos nuestra fe, cuando establecemos una relación de confianza con alguien tomándolo bajo nuestra protección o prestándoles dinero, confiándonos a su protección o tomando dinero prestado. (Agamben, 2013)

Utilizando la palabra pistis (fe), término griego utilizado por Jesús, Agamben agrega, "fe no es más que el crédito de que gozamos ante Dios y del que la palabra de Dios goza en nosotros desde el momento en que creemos en él" (Agamben, 2013). Remitiendo a la figura de Pablo de Tarso y su frase, fe es la sustancia de las cosas esperadas, "es la credibilidad a la realidad y a lo que no existe todavía, pero en lo que creemos y tenemos fe, en lo que hemos puesto en juego nuestro crédito y nuestra palabra" (Agamben, 2013). Aterrizando este análisis a un ámbito político-económico, el crédito que brinda el sistema bancario sentencia a la deuda constante, por no decir permanente, frente a su operar, siendo "el dinero un crédito basado sólo en sí mismo y que no refleja nada más que a sí mismo" (Agamben, 2013). Dichas consideraciones permiten volver y entender de manera más clara el tema de la destrucción que menciona Benjamin, tomando en cuenta que el hombre moderno profesa, involuntaria o implícitamente, la religión capitalista. Es decir, ya no existe una reformación ética en su actuar por parte del capitalismo, sino una condena destructiva a la hora de adorar el culto impuesto, siendo participe de una "morosidad divina" frente al capital. William Rasch, en su texto Schuld als Religion (La culpa como religión), presenta una frase que engloba, de manera muy lúcida, el tema de la desesperación como sinónimo de destrucción, ya que "la universalidad de la culpa que impone el capitalismo es llevada a tal extremo que la desesperación se transforma en esperanza, la esperanza de una completa destrucción del mundo tal como lo conocemos" (Rasch, 2003, 262). 
Es preciso delimitar la hipótesis benjaminiana de la relación entre capitalismo y cristianismo, ya que demarca criterios basados en la fe admitida. Al ser una religión sólo basada en la fe, sus seguidores viven sola fide, es decir sólo por medio de la fe. Continuando con el análisis de Benjamin, la religión del capital, al momento del culto, se ha emancipado de todo objeto y la culpa de toda manifestación redentora, es decir, desde el punto de vista de la creencia, queda desprovista de todo y cualquier objeto. En palabras de Agamben, "cree en el puro hecho de creer" (Agamben, 2013), o sea, en el puro crédito que es el dinero, transformándose en el dios de esta religión. $\mathrm{Al}$ articular la extrapolación de aspectos religiosos al tema del capitalismo, cabe preguntar dónde yace este nuevo dios. La respuesta es simple: el banco. Usando el recurso de otorgar características de lugares o espacios a otros- tal como en su momento Georges Bataille se refirió al museo moderno como un matadero (Bataille, 2008, 50) o Siegfried Kracauer al hall del hotel como una iglesia (Kracauer, 2010, 59-71) vemos que la iglesia del capitalismo es el banco, donde regula el crédito y administra, bajo su propio criterio, la fe depositada. El zenit del dios capitalista ya no se encuentra en las alturas, sino en un edificio donde se almacena la figura del dinero, el cual hasta en un nivel ornamental en su diseño se puede comparar con las imágenes de los santos o mejor conocidas popularmente como santitos o estampitas. Si bien Benjamin no se dedicó a explicar en extenso dicha comparación, no resulta insignificante que inclusive en detalles tan mínimos, el cristianismo y el capitalismo presenten rasgos que presentan una conexión. De esto se desprende, de forma sacra que "exista un espíritu que habla en la ornamentación de los billetes" (Benjamin, 2017, 131). Desde la lectura de Benjamin, se puede arriesgar a la reinterpretación del anuncio de la muerte de Dios, por parte del hombre frenético nietzscheano (Nietzsche, 2013, 180-181), ya que con el actuar desenfrenado del capitalismo y la nueva figura divina que rige el andar de los sujetos, este dios está más vivo que nunca, alimentando y satisfaciendo la fe que éstos le declaran, al sacralizar los espacios económicos que funcionan como horizonte en el diario vivir.

\section{La religión capitalista en el espacio urbano y la literatura}

Agamben verá que el concepto de religión planteado por Benjamin remite en su etimología al término latino de re legere, y no re ligare como unión de 
un vínculo perdido, sino en relación a "releer" las fórmulas para respetar la separación y disociación entre los órdenes de lo sagrado y lo profano (Agamben, 2005, 99). El filósofo italiano propone leer el concepto de religión como fórmula que permite mantener esa separación, y la profanación como aquello que pretende su unión. Lo que sería específico de la religión capitalista, entonces, es que ella realiza "la pura forma de la separación, sin que haya nada que separar" (Agamben, 2005, 107). Esta idea es la que recorrería el texto benjaminiano, pues las características que expone evidencian una modernidad atravesada por la imagen de una fisura, aparentemente constitutiva. Lo cual puede ser analizado desde la lectura estética del propio Benjamin, a pesar de las nuevas formas que ha adquirido el capitalismo de introducirse en la vida de los hombres. A través del surgimiento de estas nuevas modalidades que han servido de complemento para el ejercicio del capitalismo actual, se puede encontrar que, sólo por citar un ejemplo, los espacios recreativos, de reunión o esparcimiento, han ido evolucionando como lugares de consumo improductivo. Estos espacios, como los centros comerciales o shopping mall, integran en su decoración componentes propagandísticos que obligan el remontamiento al germen de su origen. Si bien el uso de la propaganda, tal como la conocemos y vivimos en nuestra actualidad, se remonta a la época de los grandes sistemas totalitarios (fascismo, nazismo), no tiene la orientación de aniquilar ni poner a la patria por sobre todo, pero sí una finalidad que no se aparta de un uso descarnado, es decir, el consumo. El impacto visual, o dicho de otra manera, la violencia visual que produce la propaganda, tanto en los espacios abiertos de la ciudad como en espacios comerciales cerrados, es decisivo para que se produzca un interés, y por qué no decirlo, una necesidad, que en muchos casos ni siquiera es necesaria, de ser partícipe del consumo. La repetición en el uso propagandístico de la imagen, se muestra como un recurso muy útil, ya que se hace presente como un bombardeo a la visualidad del consumidor, donde dicha violencia visual se hace mucho más activa, en donde se pueden encontrar ecos de La obra de arte en la época de su reproductibilidad técnica. Si bien, unos párrafos atrás se menciona al banco como la nueva iglesia, no sería impertinente atribuirle características cultuales al shopping mall, funcionando así como otro templo del capitalismo. No es menor que en dicho espacio, circulen, como forma de procesión, caravanas humanas que desembolsan la fe depositada en el dinero, teniendo como único anhelo el consumir. El capitalismo se ha hecho presente en prácticamente 
todos los ámbitos de nuestra época, inclusive en la apropiación de la misma naturaleza. Así, "la mercancía, la última gran lupa de la apariencia histórica, celebra justamente su triunfo cuando es ya la propia naturaleza la que adopta el carácter de mercancía" (Benjamin, 2013, 553). Si bien dicha cita se enmarca en una reflexión que hace Benjamin sobre el tema de la prostitución en la época moderna, tema que no convoca el presente análisis, no deja de ser interesante que inclusive en ese tema, hayan cambiado las formas de llevar la cosificación de la mujer al momento de ejercer el comercio sexual, donde el fetiche-mercancía resultó tan atractivo para la burguesía de la época, donde

[...] la moderna publicidad muestra también hasta qué extremo es posible fusionar los atractivos de la mujer y la mercancía. La sexualidad, antes movida socialmente por una fantasía del futuro que corresponde a las fuerzas productivas, ahora lo es por aquella otra correspondiente al poder del capital. (Benjamin, 2013, 554)

Para hacer más latente la relación de Benjamin con los espacios urbanos de la actualidad- tema donde él mostró gran interés- es útil volver la mirada hacia el París que él vivió y recorrió. En la mencionada ciudad, existen los denominados Passages, galerías que maravillaron a Benjamin hasta el punto que le entregaron los cimientos para elaborar su obra más ambiciosa, pero jamás terminada, Das Passagen-Werk. Estos espacios estaban diseñados para ofrecer al visitante el placer de mirar, de atraer a los buscadores de placer. Es aquí donde entra en escena un personaje trabajado por Benjamin, que lo toma de una de sus más grandes influencias, Charles Baudelaire. Se trata del flâneur, un tipo que deambulaba sin rumbo por las calles parisinas, abierto a todas las expresiones que captaba de la experiencia moderna de la urbanidad, el cual, desde la óptica benjaminiana, era fruto de la alienación propia de la ciudad y del capitalismo. Invocaba la sensación placentera de permanecer dentro de un espacio construido con estructuras de hierro que se encontraban envueltas con diseños arquitectónicos tomados de épocas clásicas y que poseían una techumbre de vidrio, lo cual permitía tener la visualidad del cielo.

En este punto, es necesario citar extensamente a David Frisby, quien en su obra Paisajes urbanos de la modernidad, ha puesto en relieve esta figura en pos de vislumbrar esta nueva lógica que abre la modernidad: 
En los escritos de Benjamin, el flâneur es algo más que una figura histórica en el contexto urbano: también funciona como metáfora contemporánea de su propia metodología. En este sentido, el flâneur/detective es una figura central, que Benjamin usa a fin de iluminar su actividad y el método que siguió para llevar a cabo el Proyecto de los pasajes, junto con las del alegorista arqueólogo/crítico y el coleccionista de desechos. En consecuencia, una investigación de la flânerie como actividad debe explorar las actividades de la observación (incluida la escucha), la lectura (de la vida y los textos metropolitanos) y la producción de textos. En otras palabras, la flânerie puede asociarse a una forma de mirar, observar (la gente, los tipos sociales, los contextos y las constelaciones sociales); una forma de leer la ciudad y su población (sus imágenes espaciales, su arquitectura, sus configuraciones humanas), y una forma de leer textos escritos (en el caso de Benjamin, tanto de la ciudad como del siglo XIX: como textos y de textos sobre la ciudad, incluso textos que funcionan como laberintos urbanos). (Frisby, 2007, 42)

Pero no hay que olvidar que la figura del flâneur no es estrictamente baudelaireana, pues tanto Balzac como Flaubert elaboraron visiones en torno a éste. David Harvey en París, capital de la modernidad, que juega directamente con el texto de Benjamin titulado París, capital del siglo XIX, texto considerado como resumen del Libro de los Pasajes, analiza este personaje en estos distintos escritores, situando en cada caso sus particularidades. En este punto, es fundamental comprender por qué Benjamin fundamenta su análisis a partir de Baudelaire y no de otros escritores, también leídos en la época, cuestión que no responde meramente a un estilo escritural. A partir del análisis del geógrafo inglés, se puede decir que

El análisis de este cambio arquitectónico y topográfico se vio transliterado en la literatura tanto de Balzac, Flaubert como de Baudelaire a partir de la aparición de la figura del flâneur. "El flâneur de Balzac es algo más que un esteta o un observador reflexivo, también está tratando de penetrar el fetiche, buscando deliberadamente desvelar los misterios de la ciudad y las relaciones sociales" (París, 75) dice David Harvey; en contraposición al que Baudelaire nos presentaba, "que es resuelto y activo en vez de desmotivado y sin rumbo" (París, 76), tomando en este punto la primera caracterización una actitud democrática: todos pueden ejercer ese rol, 
todos pueden transformarse en flâneur. Cuando Balzac escribió que "la esperanza es la memoria que desea" no está diciendo que la esperanza es la que guía la memoria, sino que es la memoria la que genera esperanza en cuanto conectada al deseo. "Quizá fue por esta razón por la que tanto Víctor Hugo como Baudelaire consideraban a Balzac un pensador revolucionario, a pesar de sus ideas políticas reaccionarias" (París, 73). Este personaje tiene en común el ser un otro a la masa que deambula por la ciudad en busca de consumo, paseando por los pasajes de vidrio y hierro, y las grandes avenidas que Haussmann inauguró, sin embargo desaparece frente al fenómeno de la sociedad de masas. La diferencia entre la visión de Balzac y la de Baudelaire nos indican otro punto más: la elección de Karl Marx por retomar la literatura del autor de la Comedia humana - a pesar de su postura política-, y la de Walter Benjamin por la del autor de Las flores del mal: el revolucionario y el marginado. (Cápona, 2016, 288-289)

Ahora bien, como menciona Harvey, Flaubert propone otra alternativa:

El flâneur, en el mundo de Flaubert, representa la anomia y la alienación, en vez del descubrimiento. Frédéric en La educación sentimental es un flâneur que vaga por la ciudad sin tener claro ni dónde está, ni el significado de lo que hace. "Frédéric nunca percibe [la ciudad] con claridad", la "línea entre realidad y ensoñación" permanece siempre borrosa. (Harvey, 2008, 115)

Esta triple visión de un personaje encarna una elección determinada de Benjamin por una cuestión específica: la fantasmagoría inserta en la ciudad en virtud de la mercancía, categoría central en la obra de Marx, pero que el filósofo berlinés reapropia -mediatizada por su lectura de Bertolt Brecht-, en otro sentido, y se podría decir también, criticando en parte la noción de fetichismo de la mercancía -a la cual si bien, se acerca-, en virtud de la famosa separación entre estructura y superestructura, prefiriendo por lo tanto, la noción de fantasmagoría. Si bien no hay aún un consenso en la fecha de su aparición, fantasmagoría sería el concepto que designa un campo de experiencia. Susan Buck-Morss lo identifica como un término que tuvo su origen alrededor de 1802 en Inglaterra para nombrar una serie de exhibiciones de ilusiones ópticas de linternas mágicas. Sin embargo, no sería este su origen exacto, ya que los espectáculos fantasmagóricos aparecieron hacia fines del siglo XVIII con la figura de Etienne Gaspar Robert, conocido como Robert- 
son. A diferencia del concepto de fetichismo de la mercancía de Marx, el concepto de fantasmagoría, incluso en su acepción marxista como ilusión óptica, estaría históricamente vinculado, aunque con un siglo de anticipación, a los comienzos de la cinematografía y a una serie de hechos que redimesionan la materialidad de las imágenes, y es esto precisamente lo que Benjamin quiere dilucidar con esta noción, una materialidad de las imágenes que transforma la vida de los hombres, pues se trata de la modulación de un campo de experiencia mediante imágenes que reproducen el modo de producción capitalista, y con ello, permite que el espacio y la vida misma de los hombres se encuentren al servicio de tal reproducción.

Ahora bien, el flâneur baudelaireano desaparece en los shopping, suprimiendo la percepción espacio-temporal de la permanencia del lugar. Si bien lo podemos considerar al momento de realizar una alusión al actual deambulador de centros comerciales, existen incompatibilidades a la hora de poner en manifiesto ambas personalidades, ya que, haciendo caso del postulado de Benjamin, el flâneur llega a su fin con la irrupción de las sociedades de consumo. A nivel de la masa que se gesta al interior de nuestros espacios comerciales, el paseante pierde su calidad de sujeto al estar en la misma sintonía que los demás, situación que se extiende a todo lugar donde opera la lógica de masas. Ya no es ese hombre desocupado que era el flâneur, que aunque se encontrara dentro de la multitud, conservaba la intensidad de su estampa personal. Tal como se mencionó anteriormente, el flâneur sentía el placer de mirar mientras visitaba los Pasajes de París, donde su mirada triunfaba, transformándolo en ese detective amateur que menciona Benjamin en sus textos sobre Baudelaire.

\section{La constitución de la ciudad: Imagen y política de la fantasmagoría}

Ahora bien, ¿podemos extrapolar dicha sensación al actual visitante de un mall? Bajo la necesidad y condicionamiento de la lógica del consumo, la actitud del flâneur se traduce en la aparición de una frustración al momento de estar frente a una vitrina comercial. Si bien no siempre se cuenta con el dinero para comprar, existe esa fe para concretar la compra, es decir y dentro de la explicación de Benjamin, contamos con el crédito para hacerlo. La culpa se hace presente, pero al mismo momento aparece la esperanza y tranquilidad al saber que se contará con una forzada facilidad de pagar poco a poco el o los 
productos, generando la deuda cultual de la religión capitalista. Hoy en día, quien concurre a los centros comerciales, no puede ver sin pagar, lo cual era una de las recompensas del flâneur.

Tal como señala el sociólogo polaco Zygmunt Bauman en su Ética posmoderna:

[...] las arcadias (pasajes) ya no existen, y dónde aún se encuentran, parecen preservados por el empeño de la herencia en su esplendor prístino, ahora inútil; una atracción turística, quizás un refugio nostálgico para aquellos que todavía recuerdan algo que les causa nostalgia, alejados del camino trillado (avenidas, vías rápidas), donde se desarrolla la acción. (Bauman, 2005, 200)

El análisis que realiza Benjamin frente a los fenómenos sociales-urbanos surgidos en la modernidad, permite poder referirnos a una actualidad de su pensamiento, sin necesidad alguna de forzar sus postulados, donde un filósofo como Georg Simmel no puede olvidarse a la hora de revisar las diversas influencias que tuvo el filósofo berlinés; un libro como Filosofía del dinero (Philosophie des Geldes) del año 1900 aparece como una obra que marca la elaboración teórica de Benjamin, al momento de referirse al fenómeno del capitalismo, en cuanto pone énfasis no en el aspecto de la producción, como Marx, sino en el del intercambio, relativizando de esta forma el concepto del valor y analizando lo que Marx denominó fetichismo de la mercancía, pero acotando a que este fenómeno es sólo una parte de uno total que involucra los contenidos de la cultura (Simmel, 2013). Cabe mencionar que Simmel fue el primer filósofo de la modernidad urbana, basándonos en el sentido inaugurado por Baudelaire respecto a la experiencia de la modernidad. Entonces, ¿dónde queda la fantasmagoría en este entramado urbano de la modernidad? La ciudad misma es ese espacio inundado por la fantasmagoría, es el espectáculo de la mercancía que se expresa tanto en su arquitectura, en su paradigma económico-político como en su aspecto social. Este velo que cubre la ciudad, esta fantasmagoría es precisamente la consideración del capitalismo como religión; es, más allá de una lectura de economía política y movimiento de capital, una forma estética que el hombre recibe y se apropia, es pues, el nuevo espíritu del capitalismo. 
Por este motivo, es importante recalcar aquello que Marx sostenía, sacado de Saint-Simon: "ningún orden social puede cambiar sin que los rasgos de lo nuevo se encuentren en el estado existente de cosas" (Harvey, 2008, 25). La admiración de Marx por Balzac era precisamente porque encontraba en su obra un carácter previsor en relación con la evolución del orden social. Con esto, el gran hito de la modernidad que borra su pasado para hacer tabula rasa a partir de 1848, es más bien una creación destructiva que en su presente mantiene latente su carácter revolucionario; este carácter es precisamente el que la obra de Balzac pone en evidencia sobre el París de 1830 y 1840, pero cuya realización se encuentra en las transformaciones del Segundo Imperio. El París del Segundo Imperio, cuya transformación es encabezada por Haussmann, reorganiza a gran escala la espacialidad de la ciudad para cambiar sus paradigmas tanto en los materiales de su construcción -el fierro y el vidrio-, sus nuevas formas -Pasajes-, su política antirevolucionaria -grandes avenidas para desarmar la herramienta de los revolucionarios: las barricadas- y finalmente, pero a nivel macro, el capital en cuanto que éste logra configurar el diseño urbano a su imagen, lo cual se ve de manera más evidente en lo que respecta a las transformaciones viales. En París esto se ve en el trazado radial de las grandes avenidas hacia L'Arc de triomphe, siendo paradigma no sólo de la conexión, sino también de la fluidez. Esta idea ha sido recuperada en la lectura de Marshall Berman, quien ve esta forma de urbanización en Robert Moses -quien parecía ser el Haussmann del siglo XXI- en el Bronx, Nueva York, con la instauración de autopistas que pretendían dejar obsoleto el modelo de la ciudad para instaurar una nueva realidad superurbana (Berman, 1994, 303-328). El autor de Todo lo sólido se desvanece en el aire, formula una tesis que nos concierne:

Una de las grandes diferencias entre el siglo XIX y el XX es que nuestro siglo ha creado una red de nuevas aureolas para reemplazar las que Baudelaire y Marx arrebataron. [...] El signo distintivo del urbanismo del siglo XIX fue el bulevar, un medio para reunir materiales y fuerzas humanas explosivos; el sello del urbanismo del siglo XX ha sido la autopista, un medio para separarlos. (Berman, 1994, 165)

Lo que pretende este cambio geográfico es precisamente hacer la ciudad a imagen y semejanza de la circulación y acumulación de capital, de allí que surja la fantasmagoría en términos de Benjamin, o en palabras de Marx, el fe- 
tichismo de la mercancía. No se trata aquí meramente del aspecto económico, sino de la representación estética que aflige al hombre en virtud de esta transformación. En este sentido es que Benjamin recogerá la imagen del flâneur de Baudelaire y sus referencias a la ciudad en cuanto crítica a esta modernidad cuya raigambre se articula en la transformación geográfica, espiritual y estética, en virtud del proceso de cambio de paradigma del capital a partir de la revolución industrial y las condiciones políticas de París de mitad del siglo XIX. Es por esto que Benjamin afirma "¿Qué otra cosa puede significar esto sino que la topografía es el plano de este espacio mítico de tradición, como lo es de cualquier otro semejante, y que realmente se puede convertir en su llave?" (Harvey, 2008, 33). La ciudad, en cuanto ha devenido espectáculo y fantasmagoría, es la llave para comprender la historia y la política, no es mera ilusión óptica sino un fenómeno de la vida cotidiana que desentraña las lógicas de poder. Por ello el rol de los marginados, los "vencidos de la historia", el flâneur, entre muchos, van a ser elementales para Benjamin en cuanto a su potencialidad política; en cuanto tales, no son los burgueses que disputaron la Revolución Francesa, sino aquellos que, dentro de la fantasmagoría de la modernidad que encarna París -ese París como la capital del siglo XIX-, son los que son capaces de penetrar en el fetiche, intentar develar esta lógica inversa de relación entre las cosas. De allí que desentrañar topológica y literariamente la ciudad, no sólo la hace legible, sino que además permite vislumbrar el factum de la fantasmagoría como gesto político; desentrañar la lógica estética del espectáculo de la mercancía en su aspecto fantasmal es precisamente lo que permite repensar las consideraciones en torno a lo político.

Es por ello que Benjamin distinguía en el París del siglo XIX la capital del consumo y la moda y, en cuanto escenario cultural de la modernidad capitalista, se le ofrecía como clave para descifrar la ilusión de la novedad que las mercancías encarnaban. La ciudad con sus Pasajes y grandes galerías, bajo su óptica, cristalizaba la fantasmagoría en su fetiche. Los Pasajes como lugares de la exposición de las mercancías eran también los lugares de los sueños y fantasías de la burguesía, así como las ruinas recientes de las mercancías caídas en desuso. El filósofo berlinés expresará que

Así como existen lugares entre las rocas del mioceno o de la edad eocénica que conservan la huella de enormes monstruos de esas épocas geológicas, así hoy los Pasajes yacen en las ciudades como cuevas que contie- 
nen fósiles de un ur-animal aparentemente extinguido: los consumidores de época preimperial del capitalismo, los últimos dinosaurios de Europa. (Buck-Morss, 2001, 82)

Lo que desea Benjamin es despertar al mundo de su sueño y, en palabras de José Sazbón, "mientras Marx penetra en el fetichismo de la mercancía y su 'halo místico', Benjamin reconsituye la poesía de la mercancía y su aura fantasmagórica (Sazbón, 1993, 95). Como ha observado David Frisby, Benjamin intentó descifrar las experiencias fundamentales de la modernidad en los lugares menos evidentes. En una sociedad productora de mercancías, el valor convierte todos los productos del trabajo en un jeroglífico social. Vemos esto de manera muy clara en el cierre del Konvolute X, donde se aprecia que

[...] la cualidad fetichista que adquiere la mercancía afecta a la misma sociedad productora de mercancía, no ciertamente como ella es en sí, sino tal como continuamente se imagina a sí misma y cree comprenderse cuando se abstrae del hecho de que precisamente produce mercancías. La imagen que de este modo produce de ella misma, y la que suele intitular como su cultura corresponde al concepto de fantasmagoría. (Benjamin, 2007, 680)

En contraposición a Marx, como lo señala Susan Buck-Morss, la apariencia fantasmagórica de la modernidad que Benjamin interpreta bajo el signo del fetichismo, no trata de la mercancía en el mercado como de la mercancía en exhibición (Buck-Morss, 2001, 98), ejemplo de esto es la referencia según la cual el autor vislumbra en los Pasajes el templo original del capitalismo de las mercancías. El significado que irá adquiriendo para Benjamin el carácter fantasmagórico de la cultura capitalista moderna habría que situarlo en el contexto de discusión con la tradición marxista, cuya contribución se situaría en el ámbito de la superestructura cultural del capitalismo como complemento de la elaboración por Marx de las articulaciones de la estructura económica, debido a que

[...] si se preserva la figuración espacial que distribuye en dos niveles superpuestos la esfera de la producción material (que es también la de la explotación) y la esfera de las producciones espirituales (que es también la de la ilusiones), encontramos el siguiente escenario desdoblado de la mercancía, tema uniforme de Marx y de Benjamin. A la esfera de su producción corresponde en El Capital, una descripción en términos clasicis- 
tas: la fábrica es el infierno de Dante; a la esfera de la circulación corresponde, en la Obra de los Pasajes, una figuración en términos modernistas: son los paraísos artificiales de Baudelaire (Pero hay que agregar que, para Benjamin, el París de Baudelaire tiene su propio infierno o, al menos, su habitante, el chiffonnier, que vive en las catacumbas y produce el horror en la gente de la superficie). (Sazbón, 1993, 95)

Vemos de esta manera que el horror que produce la modernidad en pos de la catástrofe y el progreso se encarna en la dialéctica de lo siempre igual bajo esta figura alegórica que es el infierno. Como observa Buck-Morss, es la afirmación de que el desarrollo de la modernidad social se produjo como un proceso creciente de desmitificación y desencantamiento del mundo social (Buck-Morss, 2001, 279-280). En contra de esta posición de producción, para Benjamin, el capitalismo, bajo el régimen de mercancías, produjo un reencantamiento del mundo social, a cuyo servicio estuvo el mito del progreso histórico, mediatizado precisamente por las imágenes, tanto por su masificación como por el ejercicio de visibilidad que pone en práctica una transformación material en la vida de los hombres, precisamente en la idealización de las mercancías con su novedad y moda.

Para concluir, la vigencia de las ideas de Walter Benjamin a la hora de generar posturas críticas frente al actuar de un sistema económico tan depredador como lo es el capitalismo - y con mayor razón en la presente fase que nos toca vivenciarlo - parece no perder fuerzas. Si bien, el capitalismo en su fase neoliberal actual todavía mantiene un espíritu, no es de igual forma al que vivenció nuestro autor, aun cuando ni se imaginara el devenir del capital. Para finalizar, podemos remontarnos al cierre de la tesis IX del texto sobre el concepto de historia, donde nos encontramos con el concepto de progreso (Benjamin, 2009, 44). Si bien el contexto donde fue escrito el mencionado texto era diferente al que nos ocupa hoy en día, parece que esa tempestad que sopla y desplaza al ángel de la historia que refirió Benjamin se hace presente en pos de un avance que promete un futuro mejor, pero a costa de la culpa, el endeudamiento permanente y la sacralidad hacia un culto que adoptó la forma del dinero, donde

[...] la religión capitalista, de acuerdo con la tesis de Benjamin, vive de un endeudamiento permanente, que no puede ni debe extinguirse [...] donde los individuos y familias están tan implicados en este continuo y generali- 
zado acto de fe en el futuro. Y la banca es el sumo sacerdote que administra a los fieles el único sacramento de la religión capitalista: el crédito-débito. (Agamben, 2013)

\section{Referencias bibliográficas}

Agamben, Giorgio (2005). Profanaciones. Buenos Aires: Adriana Hidalgo editora.

Agamben, Giorgio (2013). "Walter Benjamin y el capitalismo como religión". Consultado en: https://artilleriainmanente.noblogs.org/ post/2018/05/26/agamben-capitalismo-religion/

Bataille, Georges (2008). La conjuración sagrada. Ensayos 1929-1939. Buenos Aires: Adriana Hidalgo editora.

Bauman, Zygmunt (2005). Ética posmoderna. México: Siglo XXI Editores.

Benjamin, Walter (2009). La dialéctica en suspenso. Fragmentos sobre la historia. Santiago de Chile: LOM ediciones.

Benjamin, Walter (2017). “Capitalismo como religión”. En Walter Benjamin, Obras Libro VI. Fragmentos de contenido misceláneo. Escritos autobiográficos. Madrid: Abada.

Benjamin, Walter (2007). Libro de los pasajes. Madrid: Ediciones Akal.

Benjamin, Walter (2013). Obras Libro V/vol.1. Obra de los pasajes (vol.1). Madrid: Abada.

Berman, Marshall (1994). Todo lo sólido se desvanece en el aire. La experiencia de la modernidad. México: Siglo XXI Eds.

Buck-Morss, Susan (2001). Dialéctica de la mirada: Walter Benjamin y el proyecto de los pasajes. Madrid: Antonio Machado Libros.

Cápona, Daniela (2016). "El complejo ciudad-arquitectura en la lógica del capitalismo: despolitización de la cotidianeidad". Revista Alpha, No 42, pp. 285-295.

Frisby, David (2007). Paisajes urbanos de la modernidad: exploraciones críticas. Buenos Aires: Universidad Nacional de Quilmes, Prometeo Libros. 
Harvey, David (2008). París, capital de la modernidad. Madrid: Akal.

Kracauer, Sigfried (2010). La novela policial. Un tratado filosófico. Buenos Aires: Paidós.

Marx, Karl (2016). El fetichismo de la mercancía (y su secreto). La Rioja: Pepitas de calabaza.

Nietzsche, Friederich (2013). La ciencia jovial («la gaya scienza»). Valparaíso: Universidad de Valparaíso Editorial.

Rasch, William (2003). "Schuldals Religion”. En Dirk Baecker (ed.), Kapitalismus als Religion. Berlin: Erich Schmidt Verlag, pp. 249-264.

Sazbón, José (1993). "Historia y paradigmas en Marx y Benjamin”. En Gabriela Massuh y Silvia Fehrmann (eds.), Sobre Walter Benjamin. Vanguardias, historia, estética y literatura. Una visión latinoamericana. Buenos Aires: Alianza Editorial/Goethe-Institut, pp. 92-104.

Simmel, Georg (2013). Filosofía del dinero. Madrid: Capitán Swing Libros.

Toscano, Alberto (2010). "Beyond Abstraction: Marx and the Critique of the Critique of Religion". Historical Materialism. Research in critical marxist theory, No 18, pp. 3-29.

Weber, Max (2013). La ética protestante y el espiritu del capitalismo. Madrid: Akal. 